\title{
1. A history of Basic Income
}

\section{INTRODUCTION}

The writing of history requires boundaries to be set: chronological boundaries; geographical boundaries; and a set of boundaries around the particular aspects of the vast diversity of human activity with which the history will be concerned. This history has no geographical boundaries: it intends to be a worldwide history, in the sense that it is about the Basic Income debate around the world: and it also intends to be a history of the global debate, in the sense that it is a history of a debate that is now a single debate happening in many parts of the world. So this history's subject-matter will be the worldwide and global debate about Basic Income, which is defined as an unconditional income for every individual; and the period with which it will be concerned will be any period of human history in which thought or activity in relation to Basic Income has occurred.

The main tasks of this introductory chapter will therefore be to discuss the definition of Basic Income, and to set some boundaries around what the history will be about. As well as discussing the meaning of 'Basic Income', it will also explore the meanings of three other words significant for an understanding of the Basic Income debate: 'guarantee', 'unconditional' and 'universal'; and in order to decide on some important boundaries for the subject matter, it will discuss a variety of alternative reform proposals. Finally, the structure of the book will be described.

\section{BASIC INCOME}

A Citizen's Basic Income is an unconditional, automatic and nonwithdrawable income for each individual as a right of citizenship. A Citizen's Basic Income (CBI) is sometimes called a Basic Income (BI) or a Citizen's Income (CI). (Citizen's Basic Income Trust, 2018a: 3)

As this is a history about Basic Income, we need to know what we mean by that combination of words, because only then shall we know what should be included in the history. 


\section{Defining Basic Income}

When we ask about the meaning of words, we are asking how they are used. As Wittgenstein put it, 'we see a complicated network of similarities overlapping and criss-crossing; sometimes overall similarities, sometimes similarities of detail ... Now I know how to go on ... This is how these words are used' (Wittgenstein, [1953] 2001: §66, 27; §180, 62; §179, 62: italics in the original. Cf. Grayling, 1988: 90). This is how dictionaries work. Compilers collect a wide variety of usages of a word or phrase, and then attempt to capture the general meaning - the 'definition' - by using other words, which then themselves require definition, and so on (Bambrough, 1969: 94). Whilst meanings will be different in different contexts, there might be similarities in the ways in which words and phrases are used across a variety of contexts: what Wittgenstein called 'Familienähnlichkeiten', 'family resemblances' (Wittgenstein, [1953] 2001: $§ 67,27)$ : and it is on these resemblances that dictionary compilers rely. This means that if we are to know what 'Basic Income' means, then we shall have to know how it is used in a wide variety of contexts, and we shall have to look for similarities between those uses.

There is no entry for 'Basic Income', 'Citizen's Income' or 'Citizen's Basic Income' in the Oxford English Dictionary (which is interesting), but we do of course find both 'basic' and 'income'. 'Basic' used as an adjective is given a wide variety of definitions, the first two of which are as follows:

a. Of, pertaining to, or forming a base; fundamental, essential: ... b. That is or constitutes a standard minimum amount in a scale of remuneration or the like.

The dictionary also offers the following definition:

Providing or having few or no amenities, accessories, functions, etc., beyond the ordinary or essential; of or designating the lowest standard acceptable or available; rudimentary.

An example is given: 'Pastries and other sweets in the north can be pretty basic'. English as spoken in the United States of America exhibits similar meanings:

a. being the main or most important part of something ... b. very simple, with nothing special added: 'The software is very basic.' (Cambridge Essential American English Dictionary)

The somewhat derogatory undertones of the word 'Basic' in English were one of the reasons for the shift in the United Kingdom (UK) from 'Basic Income' to 'Citizen's Income' during the early 1990s. The meaning was the 
same, but the latter term was believed to escape the problem of unfortunate undertones: which of course it did not, because 'citizen' does not necessarily apply to everyone living within a jurisdiction, and so can be exclusionary. It is because the word 'Basic' was retained across most of the global debate, and 'Grundeinkommen' and 'Basiseinkommen' were the words used in the German-speaking debate, and 'revenu de base' in the French, that the UK turned to the rather more complex 'Citizen's Basic Income' terminology, and sometimes to 'Universal Basic Income' (on the word 'universal' see later in this chapter) (Torry, 2017b; 2020a: 7-27).

It is all very well deciding that the uses to which a word or phrase is put decide its meaning: but precisely whose uses of the term 'Basic Income' should we choose? Even if we decide to leave to one side the uses made of the phrase by thousands of individuals and choose to ask about the term's use by organizations, we face a substantial diversity of usage among the growing number of organizations in the field. Any organization can decide to use 'Basic Income' in whatever way it wishes, of course, but by studying what organizations say about those uses we can discover some family resemblances. For instance, most of the organizations affiliated to BIEN - the Basic Income Earth Network - would say that a Basic Income is 'unconditional' and 'individual'; and they all make identical or similar assumptions: for instance, that the payments will be regular; that they will not vary from week to week or from month to month, apart from being uprated each year; and that the levels of Basic Income might vary with people's ages.

Because BIEN is a global membership organization with affiliated organizations, its definition of 'Basic Income' is likely to reflect current usage, and in particular current usage among its affiliated organizations. The wording on BIEN's website runs as follows:

A basic income is a periodic cash payment unconditionally delivered to all on an individual basis, without means test or work requirement.

That is, basic income has the following five characteristics:

1. Periodic: it is paid at regular intervals (for example every month), not as a one-off grant.

2. Cash payment: it is paid in an appropriate medium of exchange, allowing those who receive it to decide what they spend it on. It is not, therefore, paid either in kind (such as food or services) or in vouchers dedicated to a specific use.

3. Individual: it is paid on an individual basis - and not, for instance, to households.

4. Universal: it is paid to all, without means test.

5. Unconditional: it is paid without a requirement to work or to demonstrate willingness-to-work. (Basic Income Earth Network, 2021) 
And a shorter form, last amended at BIEN's 2016 General Assembly in Seoul, reads like this:

A periodic cash payment unconditionally delivered to all on an individual basis, without means test or work requirement. (Basic Income Earth Network, 2021)

Both of these definitions represent a consensus among affiliated organizations (Torry, 2017b), and they reflect common usage of the term 'Basic Income' (although note that 'without means test' is thought to be implied by 'universal' rather than by 'unconditional', which would be a more natural connection).

The longest standing organization related to the modern Basic Income debate is the UK's Citizen's Basic Income Trust, established in 1984 as the Basic Income Research Group. It defines a (Citizen's) Basic Income as

an unconditional, automatic and nonwithdrawable income for each individual as a right of citizenship.

(A Citizen's Basic Income (CBI) is sometimes called a Basic Income (BI) or a Citizen's Income (CI))

- 'Unconditional': A CBI would vary with age, but there would be no other conditions: so everyone of the same age would receive the same CBI, whatever their gender, employment status, family structure, contribution to society, housing costs, or anything else.

- 'Automatic': Someone's CBI would be paid weekly or monthly, automatically.

- 'Nonwithdrawable': CBIs would not be means-tested. Whether someone's earnings or wealth increased, decreased, or stayed the same, their Citizen's Basic Income would not change.

- 'Individual': CBIs would be paid on an individual basis, and not on the basis of a couple or household.

- 'As a right': Everybody legally resident in the UK would receive a CBI, subject to a minimum period of legal residency in the UK, and continuing residency for most of the year. (Citizen's Basic Income Trust, 2018a: 3)

In some ways this is clearer than the BIEN definition, because it makes it explicit that although the amount of Basic Income paid might vary with someone's age, no other conditionality would apply: and so, in practical terms, everyone of the same age would receive the same amount of Basic Income. For the purposes of this book, I shall employ this simpler expression, and define a Basic Income as

an equal and regular payment of the same amount, varying only by an annual uprating, to every individual of the same age legally resident in the jurisdiction in question.

A significant definitional outlier is the way in which Ontario called an income-tested benefit a 'Basic Income' (Ontario, no date). This clearly con- 
tradicts the definitions listed above. Some uses of 'Basic Income' fall between 'an equal and regular payment of the same amount, varying only by an annual uprating, to every individual of the same age legally resident in the jurisdiction in question' and Ontario's usage. For instance, in 2019 the Green Party in the UK suggested supplements for lone parents and pensioners living alone (Green Party, 2019); and a general case has been made for making slight variations and still calling the income a Basic Income (Smith-Carrier and Green, 2017). For the avoidance of doubt: no variation in the definition will be permitted throughout this history. If something is not an equal and regular payment of the same amount, varying only by an annual uprating, to every individual of the same age legally resident in the jurisdiction in question, then it is not a Basic Income.

What will be permitted will be different terminology for Basic Income, on condition that the terminology means the same as 'Basic Income'. So texts, discussions, ideas, activities, and anything else relevant, might say that they are about 'Basic Income', 'Citizen's Income', 'Citizen's Basic Income', 'Universal Basic Income', or 'Social Dividend', and if what those terms express is a genuine Basic Income - that is, an equal and regular payment of the same amount, varying only by an annual uprating, to every individual of the same age legally resident in the jurisdiction in question - then those texts, discussions, ideas, activities, and anything else relevant, belong in this history. However, this history will employ 'Basic Income' terminology throughout. The reason for this is that what is intended is a global history, and it is 'Basic Income' that functions as the default terminology globally. 'Citizen's Income' and 'Citizen's Basic Income' are mainly found in the UK; 'Universal Basic Income' is global, but less common than simply 'Basic Income'; and 'Social Dividend' is now mainly restricted to debates about sovereign and social wealth funds, and to discussion of a Eurodividend for the European Union or the Eurozone, although during much of the twentieth century it was a common term for Basic Income. The confusingly ambiguous 'Basic Income Guarantee' is common only in the United States and Canada, and we shall not be using it. 'Basic Income' will be our default terminology, although readers might find other terminology in quotations. The reader can be secure in the knowledge that 'Basic Income' and any of the terms listed above will all be used with the same meaning: that is, they will mean an equal and regular payment of the same amount, varying only by an annual uprating, to every individual of the same age legally resident in the jurisdiction in question. If any instances of the terminology mean something else, then that will be made clear. 


\section{How Much?}

The only significant disagreement among BIEN's affiliated organizations relates to whether the definition of Basic Income should include a statement of the level at which it would be paid. A survey conducted in 2017 found that for some national organizations only an unconditional individual income at 'subsistence level', or 'sufficient to satisfy basic needs', could qualify as a Basic Income, whereas for other organizations an unconditional, regular and individual income of any amount could count as one (Torry, 2017b: 9-17). A similar division of opinion can be found in the literature on Basic Income, in which some authors assume that the level of the Basic Income should lie above a poverty line, somehow defined (Pereira, 2017: 2), whereas others do not (Torry, 2017b; 2018c; Reed and Lansley, 2016; Lansley and Reed, 2019; Martinelli, 2017a; 2017b; 2017c). This book will assume that an equal and regular payment of the same amount for every individual of the same age will be a Basic Income, whatever the level at which it is paid for each age group. This is for several reasons. 'Subsistence level' is difficult to define, with Governments often defining it in relation to political imperatives, and think tanks and social policy academics attempting more evidence-based approaches (Davis et al., 2018); social policy tends to be path-dependent- that is, policy change is more likely to be incremental than radical, even if some of the small steps might be radical—so Governments are more likely to pay attention to proposals for a Basic Income of modest size than to proposals for more substantial payments; and, most importantly, almost every individual and organization active in this policy field can agree that a Basic Income is an equal and regular payment of the same amount, varying only by an annual uprating, to every individual of the same age legally resident in the jurisdiction in question, even if they might disagree over how much should be paid. Where the amount to be paid becomes an issue in this history, the reader might find reference to terminology developed by Hermione Parker, for whom a 'Full Basic Income' meant a Basic Income at subsistence level (somehow defined), and a 'Partial Basic Income’ meant a Basic Income at a lower level (Parker, 1989: 4).

\section{Basic Income Schemes}

An essential distinction is that between Basic Income and Basic Income scheme. A Basic Income is always an unconditional income for every individual; a Basic Income scheme is a Basic Income with the different levels for different age groups specified, with the funding method fully specified, and with accompanying changes to existing tax and benefits systems also fully specified. There is of course an infinite number of different schemes, and dif- 
ferent schemes will exhibit different effects from each other and also different feasibilities (De Wispelaere and Stirton, 2004).

\section{'Guarantee', 'Unconditional' and 'Universal'}

Whilst the most important definition to discuss in relation to the global Basic Income debate is that of 'Basic Income', there are three other words that will often be found in any account of a history of the debate: 'guarantee', 'unconditional' and 'universal'.

\section{'Guarantee'}

In 1982, Brandon Rhys Williams, a UK Member of Parliament, proposed a Basic Income scheme to a House of Commons committee. Both he and his research assistant Hermione Parker called the Basic Income a 'Basic Income Guarantee', meaning by that that 'every citizen would be entitled to a personal basic income ... These guaranteed basic incomes would replace virtually all existing benefits and allowances ...' (House of Commons Treasury and Civil Service Committee Sub-committee, 1982: 425. Cf. House of Commons Treasury and Civil Service Committee Sub-committee, 1983; Parker, 1989). What was guaranteed was the Basic Income: an unconditional income for every individual; but 'Basic Income Guarantee' was ambiguous because it could mean either that the Basic Income was guaranteed, or that the Government guaranteed that an income of a certain level would be reached by each individual or household, which could imply a means-tested benefit. Largely because of this ambiguity, the word 'guarantee' was quickly dropped from the UK debate (Parker, 1985: 5), and 'Basic Income Guarantee' was replaced by 'Basic Income', 'Universal Basic Income', 'Citizen's Income' and 'Citizen's Basic Income', as they emerged one after the other and then remained as a diverse common currency.

However, for reasons that readers of Chapter 6 will understand, 'guarantee' lingered on in North America. The USBIG (United States Basic Income Guarantee) Network defines a 'Basic Income Guarantee' as a 'Government ensured guarantee that no one's income will fall below the level necessary to meet their most basic needs for any reason' (USBIG Network). 'Basic Income Guarantee' can mean Basic Income, Negative Income Tax, and similar mechanisms, all of which are understood as mechanisms for ensuring that no household incomes should fall below specified levels. As Sheahen puts it, 'Basic Income Guarantee' can encompass all of

Alaska Permanent fund, Basic Income (BI), Basic Income Grant (BIG), Citizen's Dividend, Citizen's Income, Daily Bread, Demogrant, Dividends for All, Guarantee Annual Income (GAI), Guarantee Adequate Income (GAI), Guaranteed Basic 
Income, Guaranteed Income (GI), Guaranteed Minimum Income, Guaranteed Minimum, Income Guarantee, Minimum Income Guarantee, Minimum Income, National Minimum, National Tax Rebate, Negative Income Tax (NIT), Refundable Income Tax Credit, Share the Wealth, Social Credit, Social Dividend, Social Income, Social Wage, State Bonus, Territorial Dividend, Unconditional Basic Income (UBI), Universal Allocation, Universal Basic Income (UBI), Universal Benefit, Universal Grant, Universal Income Tax Credit. (Sheahen, 2012: 178)

'Basic Income', on the other hand, always means the same thing: 'Basic Income gives every citizen a check for the full basic income every month, and taxes his or her earned income ...' (USBIG Network). This is a genuine Basic Income as defined in the previous section of the chapter. So 'Basic Income' is an unconditional income, but 'Basic Income Guarantee' is a guaranteed income level that can be met in a variety of different ways. Basic Income Guarantee and Basic Income are clearly very different concepts, but unfortunately the presence of the words 'Basic Income' in both of them means that they can easily be confused. The Basic Income Canada Network causes even more problems by defining both Basic Income and Basic Income Guarantee as income level guarantees, which implies that means-tested benefits will be paid (Basic Income Canada Network, 2021). We have already encountered the unfortunate use of 'Basic Income' to describe an experiment with an income-tested benefit in Ontario (Ontario, no date). Equally unfortunate is the assumption that the results of historic experiments with Minimum Income Guarantees in the United States can be interpreted without qualification as predicting the effects of Basic Income schemes, which of course they cannot.

The problem emerges in academic literature as well. Bent Greve suggests that increasing automation requires a 'guaranteed minimum income', but is not clear as to whether he wishes to see guaranteed a Basic Income - an unconditional income for every individual of the same age - or a minimum net household income (Greve, 2017: 95, 127) (Greve is equally confused about the meanings of Citizen's Income and Basic Income: Greve, 2017: 96). And perhaps even more problematic, Thomas Piketty employs the term 'basic income' to mean a 'minimum guaranteed income' that would 'decline as other income increased', and so a means-tested benefit: and he continues to use 'basic income' terminology while explicitly rejecting the idea of an unconditional income, on the basis that it would risk weakening the link between income and work and could be

instrumentalized to favor hyper-flexibilization and the fragmentation of labor. This could lead to an artificial inflation of the tax level, with the danger of decreasing resources available for the social state: (Piketty, 2020: 1002-3) 
none of which would occur with a carefully designed Basic Income scheme (Torry, 2020a: 77-9; 2020b).

If debate is to be rational, then clear communication between participants is essential, which in turn requires that all of the parties to a discussion should mean the same thing by the same words. Clarity matters. There is so much difference between a guaranteed minimum income and a Basic Income that it would be helpful if the term 'Basic Income Guarantee' were to be abandoned, along with all use of 'guarantee' terminology (Torry, 2020a: 22-3).

\section{'Unconditional'}

'Unconditional' is found in such combinations as 'unconditional cash transfers' and 'unconditional benefits': but what does it mean? The Oxford English Dictionary defines 'unconditional' as

Not limited by or subject to conditions or stipulations; absolute, unlimited, complete;

it defines 'condition' as:

... Something demanded or required as a prerequisite to the granting or performance of something else; a provision, a stipulation;

and the entry on 'stipulation' includes

The action of specifying as one of the terms of a contract or agreement; a formulated term or condition of a contract or agreement.

The dictionary gives as an example of the use of 'unconditional', 'The Kuwait authorities insisted that the [hijackers'] surrender was "unconditional"'; and as a use of 'condition' it offers a quotation from John Wesley: 'The word condition means neither more nor less than something sine quâ non, without which something else is not done.'

If usage is the key to a word's meaning, and we are seeking the meaning of 'unconditional' as it might be used in debate on the reform of benefits systems, then it is in such a context that we must study its use. Take these examples of uses of the words 'conditional', 'condition' and 'unconditional' drawn from an International Labour Organization publication:

Improvements in schooling are not restricted to conditional cash transfer programmes. Positive effects on schooling can also be observed for unconditional transfers or workfare programmes. ... Brazil's Bolsa Familia provides income transfers to poor households, on condition that they regularly send their children to school and that household members attend health clinics. ... In Chile, Programa de Pensiones Asistenciales, a non-contributory and unconditional social pension 
programme, is found to have reduced poverty amongst people in old age by about 9.2 per cent. (International Labour Organization, 2010: viii, 2, 11)

In relation to the first use of 'unconditional', we find the word employed in direct contrast to 'conditional', where the conditionality is clearly 'something demanded or required as a prerequisite': that is, that parents send their children to school. In relation to the second use of 'unconditional', the author adds 'non-contributory', suggesting that 'unconditional' does not preclude the income transfers being conditional on contributions having been paid. The 'unconditional' nature of the pension is clearly not compromised by its payment being conditional on the recipient's age.

We might categorize conditionalities as follows: 1. Conditions that we cannot affect (such as our age); 2. Conditions that we have affected and that relate to events in the past (such as the payment of social insurance contributions); and 3. Conditions that we can affect and that relate to future or current events (such as paid employment). The first use of 'unconditional' in the passage quoted above suggests that none of these kinds of conditions applies. The second use permits age being a condition, which is the first type of conditionality; and the fact that the pension is stated to be non-contributory suggests that here 'unconditional' does not exclude the condition that contributions have to have been paid, which is the second type of conditionality.

We find a similar variety of meanings in the modern Basic Income debate. In relation to the Citizen's Basic Income Trust's definition of Basic Income, 'unconditional' means that the Basic Income 'would vary with age, but there would be no other conditions: so everyone of the same age would receive the same [Basic Income], whatever their gender, employment status, family structure, contribution to society, housing costs, or anything else' (Citizen's Basic Income Trust, 2018a: 3). However, when Charlie Young uses the word 'unconditional' in a report for the Royal Society of Arts, sometimes it can mean 'is not dependent on other earned or unearned income, is not means-tested and is not withdrawn as earnings rise', and at other times it can mean that although the income is not subject to a work test, it can be withdrawn as earned income rises (Young, 2018: 9, 22).

Because 'unconditional' can imply a variety of meanings, even within a single document, it might be important to state a working definition for the purposes of this history. In relation to this history, unless stated otherwise, 'unconditional' should be taken to mean 'not limited by or subject to any conditions or stipulations, except the age of the recipient' (Torry, 2017a; 2020a: 10-11). 


\section{'Universal'}

The word 'universal' can be found in such phrases as 'universal benefits' and 'Universal Basic Income', and the Oxford English Dictionary defines 'universal' as follows:

Extending over or including the whole of something specified or implied, esp. the whole of a particular group or the whole world; comprehensive, complete; widely occurring or existing, prevalent over all. ... Affecting or involving the whole of something specified or implied. ... Of a service or facility: extended to, provided for, or accessible to all members of a community, regardless of wealth, social status, etc. ...

The last part of the entry is particularly relevant. The most recent example of usage given is from the South China Morning Post: 'By last year, 94 per cent of the mainland's populated areas had provided nine years of universal compulsory education.' The definition makes it clear that any use of the word 'universal' requires the specification of the community to which the 'service or facility' is extended, for which it is provided, or to which it is accessible.

We shall seek examples of the use of 'universal' in the same International Labour Organization publication that we quoted above:

But despite the progress made in the materialization of the universal right to social security, very important gaps remain. ... Non-contributory schemes include a broad range of schemes including universal schemes for all residents, some categorical schemes or means-tested schemes. ... Categorical schemes could also be grouped as universal, if they cover all residents belonging to a certain category, or include resource conditions (social assistance schemes). They may include other types of conditions such as performing or accomplishing certain tasks. (International Labour Organization, 2010: 1, 39)

The community envisaged by the first use of 'universal' is the whole of the human race; but the community envisaged by the second and third uses is constituted by the residents of places served by particular non-contributory schemes. However, the second and third uses are different. The second instance of 'universal' implies a benefits scheme that is neither means-tested nor restricted to a particular category of residents, because those kinds of benefits are listed separately. This means that the same amount will be paid to everyone of the same age, and that here 'universal' implies unconditionality. The third use flatly contradicts the second use, because it implies that universal schemes can be categorical or means-tested. So while 'universal' always means 'extending over or including the whole of something specified or implied', great care will always have to be taken when interpreting uses of the word 'universal'. It might mean that the same amount of money would be paid to every resident of a given community; or it might mean that it would be paid to 
every eligible resident, with eligibility being determined by whether someone belonged to a particular category (for instance, whether they were unemployed or disabled), or by whether their existing income fell below a specified level. The UK's 'Universal Credit' is a means-tested and work-tested benefit (and ought to be called 'Unified Benefit'), whereas 'Universal Basic Income' is another name for Basic Income: an unconditional income paid at the same rate to everyone of the same age.

As with 'unconditional', 'universal' has been used with diverse meanings, so the reader will always need to study the context in order to discover the meaning that an author is giving to the word. In this history, 'universal' will always apply to a particular community, whether national, regional or global: so 'Universal Basic Income' will mean a Basic Income paid to everyone within a specified community. Strictly speaking, the 'universal' is redundant here, because 'Basic Income' implies unconditionality, which in turn implies universality: so the purpose of adding 'universal' to 'Basic Income' is presumably to emphasize the fact that everyone in a particular community would receive the income, regardless of any circumstances other than their age. Similarly, this history will take 'universal benefit' to mean an unconditional income for a particular age group: so, for instance, the UK's Child Benefit is a universal benefit because it is paid for every child. If quotations employ 'universal' to mean something different-for instance, that an income will be paid to everyone in a community who happens to be somehow eligible to receive it - then that will be discussed.

'Unconditional' will always imply 'universal', and if 'universal' means unconditional within a community then 'universal' will imply 'unconditional'. However, if 'universal' means 'every eligible individual within a community', then 'universal' does not imply 'unconditional'. This means that we cannot automatically replace 'unconditional' with 'universal' (Torry, 2017a; 2020a: 11-13).

\section{WHAT SHOULD BE INCLUDED IN THIS HISTORY?}

Clarity of definition will be a primary concern and aim of this history. This is for two reasons. Firstly, in relation to the history itself: any history-writing requires a clear boundary to define what the history is about; and clear boundaries require clear definitions of terms. Secondly, in relation to any use to which this history might be put in connection with the global debate on Basic Income: only if definitions are clear and understood can that debate be rational. A concern for clarity of definition draws our attention to aspects of the Basic Income debate where clarity is lacking, and raises an important question as to what should be included in this history and what should not. 
Take for instance the significant recent upsurge in popular futurist literature in which Basic Income proposals are found. Two examples that argue from technological and employment market change to Basic Income are Utopia for Realists by the journalist Rutger Bregman (2017), and The Second Machine Age by Erik Brynjolfsson and Andrew McAfee (2014). Bregman tells us that he is an enthusiast for Basic Income, but many of his examples have conditionalities attached to them, and there is no initial definition against which he evaluates the different mechanisms that he discusses. Similarly, The Second Machine Age does not distinguish between Basic Income schemes and Minimum Income Guarantees that imply means-tested benefits (Brynjolfsson and McAfee, 2014: 232-3). So should these two books appear in a history of Basic Income? The fact that they are ambiguous in relation to the subject-matter might suggest that they should not: but the fact that they and books like them have been significant elements in the modern debate about Basic Income suggests that they should. The policy of this history will be that texts, discussions, experiments and anything else that has been relevant to the Basic Income debate, will be included. This means that texts, discussions, experiments and anything else about Basic Income, and also texts, discussions, experiments and other activities that are either ambiguous in relation to the central subject matter of Basic Income, or that do not relate to it at all, will be included if, and only if, such material has been directly relevant to the Basic Income debate. So yes, Utopia for Realists and The Second Machine Age are ambiguous in relation to Basic Income, but they have played a part in the modern Basic Income debate, so they are relevant to that debate's history.

Similarly, the Ontario experiment with an income-tested benefit that they called a 'Basic Income' (Ontario, no date) was not about Basic Income at all, but it had a variety of effects on the global Basic Income debate and therefore belongs in the history. And a lot further back, Thomas Paine, often credited with initiating the modern Basic Income debate, did not in fact write about a Basic Income (Paine, 1797), whereas Thomas Spence did write about one at around the same time (Spence, 1797). However, what Paine wrote was a significant contribution to the Basic Income debate, so his name and what he wrote must appear.

A particularly important question relates to whether such reform proposals as Minimum Income Guarantee, Negative Income Tax, Tax Credits (of various kinds) and Participation Income, belong in this history. The following section therefore describes those ideas, raises the important question of their administration, and asks to what extent they belong in this history. 


\section{Minimum Income Guarantee, Negative Income Tax, Tax Credits, Basic Income and Participation Income}

There are a number of ways in which a Government can provide incomes to individuals and households: by guaranteeing that a household will not fall below a specified minimum income; by implementing a Negative Income Tax, which pays out below an earned income threshold; by allocating a Tax Credit that is withdrawn as earned income rises; by providing a Basic Income: an unconditional income at the same level for everyone of the same age; or by providing a payment that would be a Basic Income if there were no behavioural conditionalities attached to it. Relationships between these different mechanisms are quite complex, which raises the question as to which of these belong in a history of Basic Income.

\section{Minimum Income Guarantee}

A Minimum Income Guarantee (MIG) is a level of income below which a household is not allowed to fall, with different levels applying to different types of household. A means-tested or income-tested benefit is then provided to fill the gap between the set level and existing earned and savings income (an income-tested benefit takes income into account when a benefit level

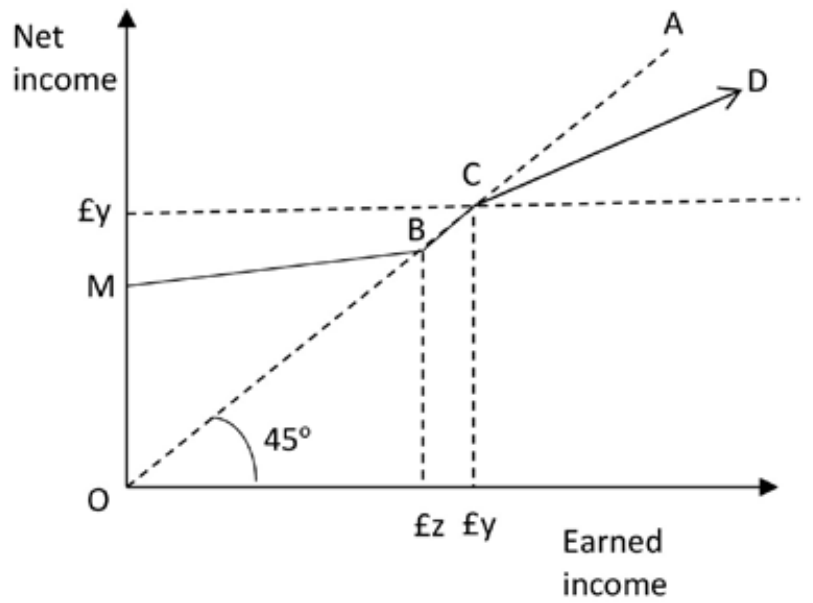

Note: $\quad$ A means-tested benefit enables a household's disposable income to reach the Minimum Income Guarantee level M. By the time earned income reaches $£ z$ the benefit has been completely withdrawn. Tax is paid from earnings level $£ y$. Net income is given by the line MBCD.

Source: Author's own.

Figure 1.1 Minimum Income Guarantee 
is calculated, whereas a means-tested benefit might take other factors into account, such as wealth) (see Figure 1.1). If the rate at which the means-tested benefit is withdrawn is the same as the rate at which income tax is paid, and if the means-tested benefit is totally withdrawn when the earned income tax threshold is reached, then the relationship between disposable income and earned income can be represented by a straight line on the graph with earned income on the horizontal axis and disposable income on the vertical axis, as in Figure 1.2.

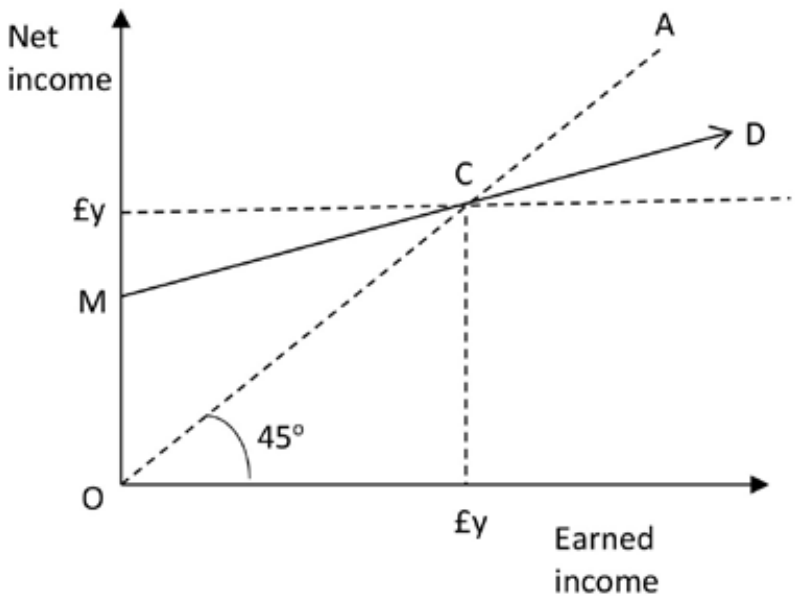

Note: $\quad \mathrm{M}$ is the Minimum Income Guarantee. If the means-tested benefit is withdrawn at the same rate as income tax is collected, and the benefit is withdrawn completely at the tax threshold $£ y$, then the relationship between disposable income and earned income is represented by the straight line MD.

Source: Author's own.

\section{Figure 1.2 Minimum Income Guarantee}

\section{Negative Income Tax}

A Negative Income Tax works in the same way but is administered through the tax system. If the employer is responsible for deducting income tax and passing it to the Government, then above a tax threshold the employer will deduct tax, and below it will pay out a Negative Income Tax proportional to the amount by which earned income falls below the threshold (see Figure 1.3). If the rates of deduction and the rate of payment are the same on either side of the threshold, then the relationship between earned income and disposable 


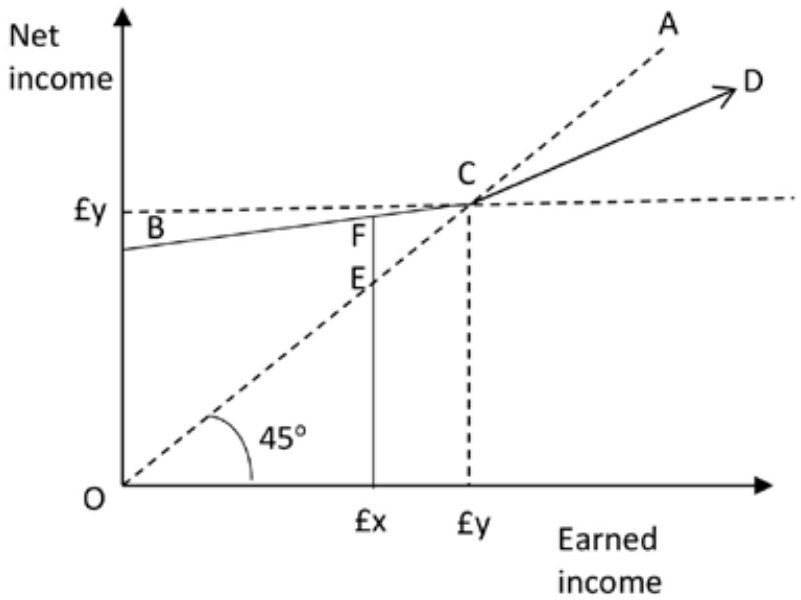

Note: $\quad$ A Negative Income Tax is paid below an earned income threshold, and income tax is deducted above it. At earned income of $£ x$, the Negative Income Tax paid out is given by the line EF. Net income is given by the line BCD.

Source: Author's own.

Figure 1.3 Negative Income Tax

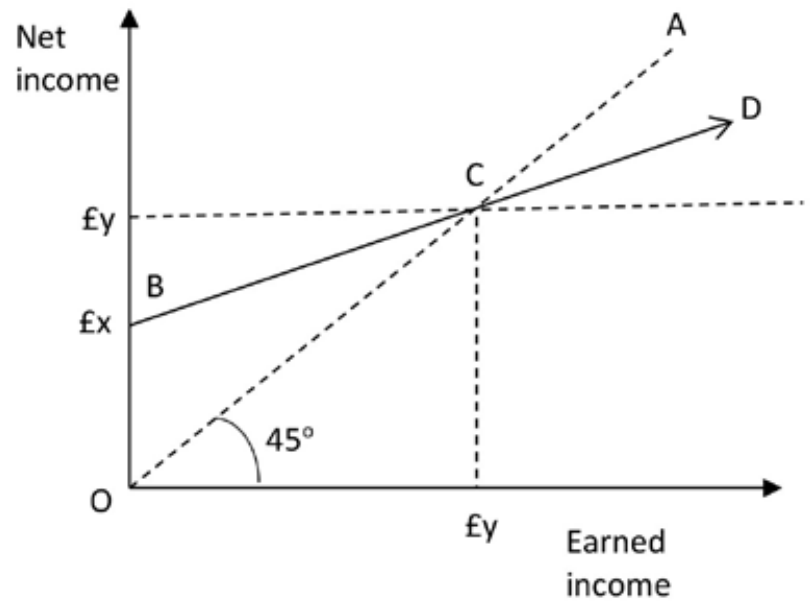

Note: Where the rate of deduction above the earned income threshold fy and the rate of payment below the threshold are the same, the relationship between disposable income and earned income is represented by the straight line BD.

Source: Author's own.

Figure 1.4 Negative Income Tax 
income will be represented by a straight line on a graph with earned income on the horizontal axis and disposable income on the vertical axis, as in Figure 1.4. If with a Minimum Income Guarantee the means-tested benefit happens to be zero at the tax threshold (that is, when income tax begins to be paid), then the Minimum Income Guarantee works in the same way as a Negative Income Tax, except in relation to its administration, on which see below.

\section{Tax Credit}

'Tax Credit' can have a variety of meanings.

a. As used by the UK's Heath Government during the early 1970s, it meant a fixed sum allocated each week to each individual by the Government. If there was no other income, then the sum would have been paid in full. As earned income rose, the Tax Credit would have been withdrawn at a specified rate until it was exhausted at an earnings threshold. Above the threshold income tax would have been charged. To specify a Tax Credit amount fulfils the same function as specifying the rate at which a Negative Income Tax would be paid below the earnings threshold (see Figure 1.5). If the Tax Credit is withdrawn at the same rate as income tax is paid, then the relationship between earned income and disposable income can be

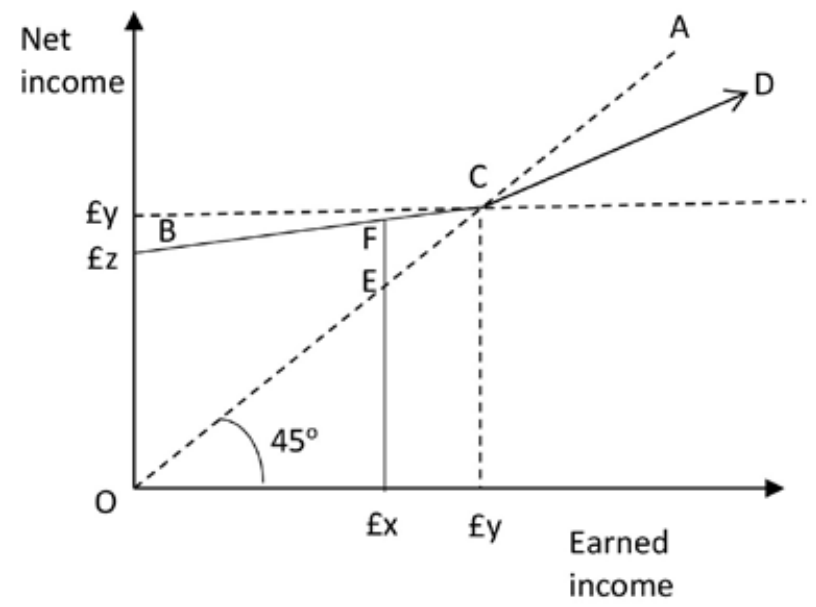

Note: $\quad$ A Tax Credit of $£ z$ is allocated. If there is no other earned income, the Tax Credit is received in full. As earned income rises, the Tax Credit is withdrawn until at earned income of $£ y$ it is exhausted. At earned income of $£ x$ the Tax Credit is represented by the line EF. Net income is given by the line BCD.

Source: Author's own.

Figure 1.5 Tax Credit 
represented by a straight line on a graph with earned income on the horizontal axis and disposable income on the vertical axis (see Figure 1.6).

b. The United States Earned Income Tax Credit (EITC) is paid annually to families in employment following the submission of an annual tax return. A formula determines the amount of EITC to be paid.

c. The 1997 New Labour Government in the UK called means-tested benefits for families in employment 'Tax Credits'.

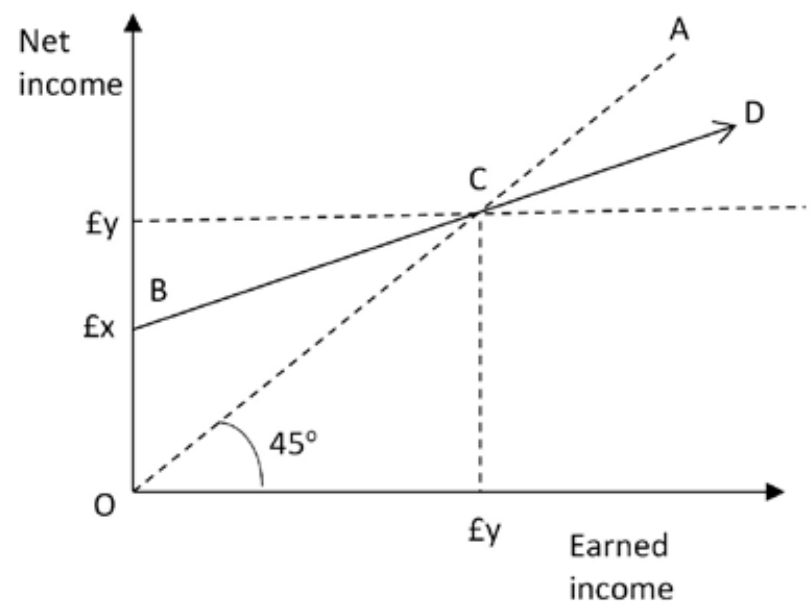

Note: $\quad$ Where the rate of deduction of tax above the tax threshold is the same as the rate of withdrawal of the Tax Credit, the relationship between net income and earned income is given by the straight line BD.

Source: Author's own.

Figure 1.6 Tax Credit

\section{Basic Income}

A Basic Income is an unconditional income paid to every individual. Figure 1.7 represents a Basic Income scheme in which the Basic Income is paid for by collecting income tax on all or most other income.

\section{Participation Income}

During the early 1990s, Professor Tony Atkinson proposed a 'Participation Income' (see Chapter 7): a Basic Income in all respects other than the conditionality that there would have to be evidence of some kind of 'participation' in society, or evidence that participation ought not to be expected. He thought that a Participation Income would be more acceptable politically than a Basic 


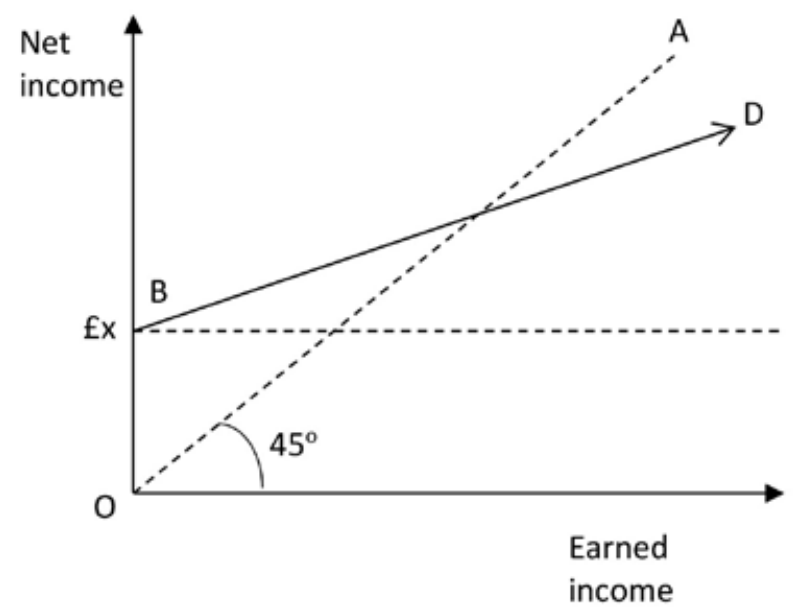

Note: $\quad$ The Basic Income of £x provides a secure financial platform. Tax is then collected on all or most other income. Net income is given by the straight line BD.

Source: Author's own.

\section{Figure 1.7 Basic Income}

Income. Those who were ill, disabled, retired or looking for work, would receive a Participation Income without having to prove participation in society, but otherwise at least one participation condition would have to be met: employment, self-employment, education, training, voluntary work, or caring for the young, older people or disabled dependents (Atkinson, 1993; 1996; Fitzpatrick, 1999: 101, 111-22; White, 2003: 170-75). (No graph has been offered in relation to a Participation Income, because this would be the graph for a Basic Income: but that graph's caption would have to make it clear that only those who satisfied one of the 'participation' conditions would actually receive the Participation Income.)

\section{Comparisons between Minimum Income Guarantee, Negative Income Tax, Tax Credit, Basic Income and Participation Income}

As we can see from the graphs, it is possible to choose parameters for means-tested benefits, Negative Income Tax and Tax Credit (definition (a)) that would enable them to exhibit the same relationship between earned income and disposable income as for a Basic Income. This can lead to an assumption that they are the same as Basic Income (Sommer, 2016). They are not. Significant differences between them, particularly in relation to their administration, mean that they are very far from being the same, and very far indeed from having the same effects. 


\section{The administration of means-tested benefits}

Means-tested benefits are usually paid in arrears by a Government agency on the basis of a calculation that relates to household composition and earned and other income. Either housing costs are factored into the calculation of a single means-tested benefit, or a separate means-tested benefit might be paid to cover housing costs. Either average earnings during a previous period of several months is used in the calculation, in which case the benefit is awarded at the same rate for several months before it is recalculated, or the income earned since the benefit was last paid is used in the calculation, in which case the benefit is recalculated for each payment. The former method can result in overpayments which then have to be repaid, causing financial problems for the household, whereas with the second method the Government agency has to know the household's earned income in real time (as with the UK's Universal Credit) so that each benefit payment can be accurately calculated. Multiple jobs, occasional earnings, varying earned incomes and other factors, make accurate administration difficult to achieve, resulting in wildly gyrating benefit levels, periods without benefits and calculation errors (Unite Research, 2019).

\section{The administration of Negative Income Tax}

Income tax deducts money from earnings above an earnings threshold, and a Negative Income Tax pays money to the employee below the threshold. The Negative Income Tax can be administered by the Government or by the employer. If the Government administers the Negative Income Tax, then it becomes a means-tested benefit calculated by the second of the two methods described in the previous section. The employer must provide regular and accurate earnings information to the Government (as with the UK's Universal Credit). If the employer administers the Negative Income Tax, then if someone moves between employers their Negative Income Tax administration has to be transferred between employers; and if they have a period of unemployment then administration has to be handed to the Government and then on to the new employer. If someone has two employments then the employers have to decide which of them will administer the Negative Income Tax; and if someone has occasional other earnings then their employer will need to be informed so that the employee can be paid the correct amount of Negative Income Tax, if any.

If every working age adult is treated in the same way for Negative Income Tax purposes, then neither their employer nor the Government needs to know any personal details. If people in different circumstances are treated differently (for instance, in relation to household structure), then their employer and the Government will need to know individuals' circumstances in order to calculate the correct income tax or Negative Income Tax.

Many income tax systems are cumulative. An annual amount of income is not taxed: so each week, or each month, the employer has to calculate how 
much tax to deduct so that by the end of the tax year the correct amount of tax has been deducted. With Negative Income Tax, the tax system would be non-cumulative. Each week, or each month, the correct amount of the Negative Income Tax would have to be paid in addition to earnings, or no Negative Income Tax would be paid and earnings would be taxed. A non-cumulative system requires a single tax rate, so anyone paying higher rate tax would have to pay additional income tax at the end of the tax year.

\section{The administration of Tax Credits}

A Tax Credit scheme of variety (a) would be administered in the same way as Negative Income Tax. The only difference would be in the specification. For a Tax Credit scheme, the amount to be paid out if there are no earnings is specified, along with a withdrawal rate as earnings rise. For a Negative Income Tax, the threshold is specified along with tax rates above and below the threshold. Administration of Tax Credits (of definition (a)) and Negative Income Tax would be identical.

\section{The administration of Basic Income}

A Basic Income is an unconditional income paid to every individual by a Government agency, and it is not withdrawn as earnings rise. Income tax is paid on all or most earned income, and this would continue to be administered in the normal way. Administration of the Basic Income would be extremely simple. As the only conditionality permitted would be someone's age, the Basic Income could be turned on at each person's birth, or at whatever age had been agreed, and could be turned off at their death. Very rarely would any active administration be required in between.

\section{The administration of Participation Income}

First of all, a test would have to be applied to find out if someone was exempt from meeting the participation conditions, and, if they were not, evidence would have to be provided that they were meeting at least one of the conditions. The test and the evidence-seeking would have to be undertaken at regular intervals.

\section{Comparing the schemes}

Administration matters. Take, for example, a Participation Income. At face value the argument that it would more politically feasible than a Basic Income might appear to be persuasive, but once we take account of the administrative realities things look rather more complicated. 'Street-level bureaucrats' (Lipsky, 1980) would find themselves with considerable discretion as they decided whether someone was exempt from meeting a participation condition, and, if they were not, whether they could meet at least one of the partici- 
pation conditions. The kind of demeaning enquiry that has always plagued means-tested benefits would have to be applied to millions of people in relation to what would otherwise be an unconditional income. Each condition would have to be minutely specified; 'creative compliance' would become a wasteful industry (De Wispelaere and Stirton, 2008; De Wispelaere and Noguera, 2012: 25-6); and, taking England and Wales as an example, this huge and stigmatizing administrative effort would exclude a maximum of 1 per cent of the population from the Participation Income (Torry, 2016a: 134-8). Public attitudes would quickly sour. Once the administrative realities are factored in, the supposed political feasibility of Participation Income begins to look rather less convincing.

Negative Income Tax and genuine Tax Credit (definition (a)) schemes would be simple to administer for any individual with a single long-term permanent employment and no other income. As we can see from the descriptions above, administering them for anyone else would present a serious challenge. And we already know how complex, stigmatizing and error-prone is the administration of the means-tested or income-tested benefit required by a Minimum Income Guarantee.

But might we have to take factors other than administration into account? Survey data from Japan suggests that a Negative Income Tax could be a more popular option than Basic Income (Takamatsu and Tachibanaki, 2014: 205), so even if the administration might be onerous, Negative Income Tax might still be preferred to Basic Income. However, the Japanese public opinion survey took no account of the difficulty of administering a Negative Income Tax, and if information on the administrative complexities had been conveyed before the survey questions had been asked then the outcome might have been different. An additional problem with the survey is that questions about Negative Income Tax were only put to people in employment (Takamatsu and Tachibanaki, 2014: 201), whereas questions about Basic Income were put to members of the public regardless of their employment status. It is difficult to see how a legitimate comparison can be made between the two sets of figures.

Here a general point must be made: few people are able to understand the complexities of the tax and benefits system of a developed country, so it is difficult to see how most people would be able to deliver a well-informed opinion about alternative income maintenance mechanisms to a public opinion researcher. A further difficulty is that, as we have recognized, the different mechanisms can look very similar if drawn on a graph. This misleads economists and other academics into thinking that they are basically the same, when they are in fact very different from each other. Both a Negative Income Tax and a Tax Credits (type (a)) scheme would be either impossible or very difficult to administer, whereas a Basic Income could not be easier. The UK's recent experience with 'Universal Credit' (a combined means-tested benefit) is 
a classic example of consultants proposing a system without taking sufficient account of the administrative challenges that the proposal would face (Centre for Social Justice, 2009), and of a Government and civil service not sufficiently aware of how benefits systems are administered in practice. A Participation Income was proposed by an eminent academic who was either unable or unwilling to factor in the complex, wasteful and demeaning administration that would be required. The only reform option that we have discussed that could be administered easily is Basic Income, and it is also the only one for which the transition from the current system would be easy to manage (Torry, 2015a).

\section{Do these reform proposals belong in this history?}

Some authors begin their discussions of the history of Basic Income with histories of means-tested and contributory benefits (Van Parijs and Vanderborght, 2017: 51-69), as the evolutions of these very different benefits have 'deeply shaped the context in which interest for basic income has developed and into which it will need to be fitted in due course' (Van Parijs and Vanderborght, 2017: 51). There is some logic to this. However, that will not be the approach of this history. This is a history of Basic Income, so an unconditional income for every individual must remain its focus. However, readers will discover references to the histories of means-tested and contributory benefits, and to the various mechanisms just discussed, where these are relevant to the main theme. For instance, Basic Income will often be found being advocated as a replacement for, or complement to, means-tested benefits, and Minimum Income Guarantee experiments have often been employed as evidence for the likely effects of Basic Income, which of course they cannot be in any direct sense. A Negative Income Tax has sometimes been argued for as a form of Basic Income (which it is not), and a Participation Income became an important element in the debate during the early 1990s, and was still being proposed by Tony Atkinson as an alternative to Basic Income not long before he died in 2015 (Atkinson, 2015: 297). This is not a history of a variety of reform proposals: it is an account of the history of Basic Income, and important elements of that history have been the ways in which other proposals have been compared with Basic Income, have drawn attention towards themselves and away from Basic Income, have been either properly or erroneously employed to provide evidence for or against Basic Income, and so on. Timothée Duverger suggests that any 'minimum income' should be regarded 'as a prefiguration or a reduced form of Basic Income' (Duverger, 2018: 6-7), and includes a variety of income-tested and otherwise conditional benefits in his history. We shall do the same where those other mechanisms are relevant to the history of Basic Income, but not otherwise: and we shall always distinguish clearly between Basic Income and other kinds of income provision. 
Any author who writes a history inevitably encounters multiple interesting aspects of the subject about which the history is being written. It is therefore tempting to detour through discussions of those aspects. While readers will find a number of such detours in this book, an attempt has been made to keep them to a minimum, and in particular to keep them to discussions that might illuminate the history of Basic Income: which is, after all, what this book is meant to be about.

\section{The Selection and Ordering of Material}

There is of course a sense in which this book is not a history of Basic Income. No country has ever implemented one, so perhaps there is no history to be written. However, as Kovce and Priddat point out, if ever a Basic Income is implemented, it will not be without a history (Kovce and Priddat, 2019: 26). However, to recognize that if ever a Basic Income is implemented it will have a history, and that here we intend to record that history from early mentions of Basic Income to the present day, does not tell us precisely what to include, nor how to order the material.

For instance: should this be a history of ideas, and of the ways in which they have emerged, evolved, and often disappeared? Should it be about texts? Should it record discussions that have taken place, among activists, academics, policymakers, and so on? Should it be a history of events: for instance, of pilot projects and experiments of various kinds, and of the implementation of unconditional incomes of various kinds? It would be impossible to separate these different aspects of the global Basic Income debate, so this history must be about all of those. Ideas and texts have driven pilot projects and experiments, and those in turn have generated ideas and texts. Discussions and texts have resulted in implementations, and implementations have resulted in ideas, texts and discussions. Although there will be a clear subject-matter boundary in the sense that the focus for this history will be Basic Income, no other restriction will be imposed on the kinds of material to be included.

However, saying that does not tell us how to choose or order the material. A study of existing histories of Basic Income reveals that several of the authors have chosen a 'waves of enthusiasm' pattern, as they have noticed that periods of substantial activity have always been followed by troughs during which the debate has subsided and has sometimes disappeared from view. The fact that authors differ in relation to how many waves there have been rather suggests that the material itself does not suggest a single waves and troughs pattern, and that the wave patterns have to some extent been imposed on the material. A study of the histories finds that in order to populate some of the waves, material that might not strictly belong in a history of Basic Income has sometimes been given rather too much attention. This applies particularly to waves 
that are better described as waves of activity in relation to Minimum Income Guarantee schemes rather than waves of activity about Basic Income schemes (Torry, 2020a: 28-47). The policy of this book will be to avoid overarching patterns, and instead to seek out material on the Basic Income debate and then to order it both geographically and chronologically. Once that has been done, patterns might be discovered.

But having described what might look like a carefully structured method backed by apparently normative processes for choosing and ordering material, it is of course essential to recognize that many different histories of Basic Income have been written, could have been written, and will be written: and as one of those who commented on an early draft has quite rightly pointed out, it would be possible to write a book about each of the many aspects of the history only briefly mentioned in this volume. This means, of course, that a vast amount of potential material has been omitted, which inevitably reduces the objectivity of the resulting history. A further related problem is that the limits imposed by the requirement to write a single-volume history has meant that much that others might have wished to see either explained or contextualized has not been. It is entirely true that what the reader will find here is a highly subjective selection and ordering of material, and I look forward to one day reading the equally subjective histories that will be written by scholars more experienced at history-writing than I am.

\section{THE STRUCTURE OF THE BOOK}

Following this introductory chapter, Chapter 2 will ask who first thought of the idea of Basic Income, and from then on a broadly chronological structure will be followed. Chapter 3 will record relevant individuals and movements during the nineteenth century; and Chapters 4 and 5 will explore the debate in the United Kingdom during the first half of the twentieth century. Chapter 6 will discuss the quite distinctive debates in Canada and the United States of America; Chapter 7 will ask about the character of recent debate in the UK; and Chapter 8 will explore the multiple approaches of the debate in continental Europe. Chapter 9 finds that during the twenty-first century debate about Basic Income has occurred all over the world; and Chapter 10 discusses what is now a single global debate. Chapter 11 draws conclusions.

\section{CONVENTIONS}

A normal convention in social policy is employed throughout the book: taxes and benefits in general are not capitalized, whereas the particular specified taxes and benefits of particular countries are, so 'income tax' means any tax on income, whereas in the context of a discussion of the UK's tax and benefits 
system 'Income Tax' will be the UK's Income Tax along with all of its regulations. Clearly defined mechanisms, such as Negative Income Tax, Tax Credit and Basic Income, will also be capitalized.

\section{A HISTORY OF BASIC INCOME}

To reiterate, this is a history of Basic Income: an individual, unconditional and nonwithdrawable regular income, of the same amount for every individual of the same age, without work test and without means test. Peter Sloman suggests that 'any attempt to understand the intellectual history of basic income must start by recognizing the fluidity of the idea and the ambiguity of many real-world proposals' (Sloman, 2019: 4-5). This history takes a different approach. As far as Basic Income: A History is concerned, the definition of Basic Income is clear and definite, and it is not fluid. The difference in the two approaches might be due to the fact that Sloman is a historian, and that for historians everything is in process, including ideas; whereas this author's first job after leaving university was the administration of means-tested benefits, and he has spent much of the last 35 years researching social policy, a field in which clear definitions are essential.

Sloman suggests that 'we can only understand the history of basic income ... in relation to a wider nexus of cash transfer schemes' (Sloman, 2019: 10), and that the history of an idea such as Basic Income requires us to understand the diverse and changing economic, social and social policy contexts within which the idea has been discussed or trialled (Sloman, 2019: 12). This no doubt correct insight underlies a number of collections of texts relating to the Basic Income debate (Cunliffe and Erreygers, 2004; Kovce and Priddat, 2019; Widerquist et al., 2013) in which texts about a 'guaranteed income' will often be found alongside texts about Basic Income. The intention in the writing of this history will be distinctive. It is a history of Basic Income: an unconditional and nonwithdrawable income for every individual: so the most significant context for any particular instance of discussion or experience of Basic Income will be discussion and practice of the same idea at different times and in different places. This book is a history of Basic Income, and other cash transfer schemes will only be discussed to the extent that they are relevant to that history. 